\title{
Performance of a single cylinder diesel engine fuelled with emulsified residual oleins and standard diesel fuel
}

\author{
E. Melo ${ }^{1}$, R. Piloto ${ }^{1}$, I. Tobio ${ }^{1}$, L. Goyos ${ }^{1}$ and S. Verhelst ${ }^{2}$ \\ ${ }^{1}$ Faculty of Mechanical Engineering, Technical University of Havana \\ Calle 127 s/n, Cujae, Marianao, Habana, 19390, Havana (Cuba) \\ Phone/Fax number:(+537) 6900142, e-mail: emelo@ ceter.cujae.edu.cu, eliezer.ahmed.melo.espinosa@gmail.com \\ ${ }^{2}$ Department of Flow, Heat and Combustion Mechanics, Faculty of Engineering, Ghent University \\ Sint-Pietersnieuwstraat 41, 9000 Gent (Belgium) \\ Phone, fax, e-mail: sebastian.verhelst@ugent.be
}

\begin{abstract}
Emulsified residual oleins and standard diesel fuel were evaluated. The engine tests for the fuels analyzed were performed in a Petter single cylinder direct injection diesel engine under steady state conditions at fixed torque values $(20$ $\mathrm{Nm}$ and $34 \mathrm{Nm}$ ) and the engine speeds $(n)$ between 1300-1700 rpm. Power output, specific fuel consumption, ignition delay and exhaust composition were evaluated. The emulsified residual oleins (ERO) shown lower power output joint to a higher specific fuel consumption related to the lower heating value of residual oleins compared to diesel fuel. A shorter ignition delay was observed for the ERO. Decreases in NOx emission were obtained for ERO compared to diesel fuel. The use of ERO in order to be a partial or full alternative to the use of diesel fuel for energy production was achieved.
\end{abstract}

\section{Key words}

Residual oleins, emulsion, ignition delay, diesel engine

\section{Introduction}

Diesel engines are mainly used in industrial, transport and agricultural applications due to their high efficiency and reliability [1]. The development of internal combustion engines followed a dual strategy over years: improvement of engine performance and reduction of pollutant emissions [2]. However, researchers as Alahmer [2], Subramanian [3] and Qi[1] sentenced that the diesel engines are considered an important pollution source, due to their emissions (black smoke, hydrocarbon (HC), nitrogen oxides (NOx), particulate matters (PM), sulfur oxides $(\mathrm{SOx})$, carbon dioxide $\left(\mathrm{CO}_{2}\right)$ and carbon monoxide (CO).

On the other hand, the increasing petroleum price and environmental concern due to global warming has developed the thrust in search of renewable fuels for diesel engines [4]. Recently, much attention has been paid to the development of alternative fuels in order to meet the emission standards and to reduce the dependency on fossil fuel [4]. In addition, the fossil fuel demand is continuously increasing the depletion of fossil fuel stocks [5].

These situations have motivated in the scientific community around the world the interest in alternative fuels. Researchers as Tan [6] and Senthil [7] point out that the animal fats and the vegetable oils represent promising alternatives to conventional fuel (diesel) because of their very close properties to diesel. But, the use of these biofuels brings several problems associated in diesel engines as less efficient combustion process due to the poor atomization process and ignition delay.

For this reason, in order to obtain a more engine-friendly fuel is necessary change the biofuels properties (viscosity, surface tension, etc) applying different method, such as: preheating, blending, transesterification, cracking/pyrolysis, emulsification, etc. The advantage and drawbacks of such method are mentioned for Kumar [8]. Also, this researcher emphasized in the trend to use the emulsions as fuel in diesel engines due to is a simple process and needs no modification in the engine design, as well as, their simultaneous reduction of smoke and NOx emissions. Alcohol-oil microemulsions for use in diesel engine is suggested by Yusuf [9].

The most important volume of petroleum used in Cuba is imported, because the sources of liquid fossil fuels are small. In order to solve this situation, with the country's resource, could be very interesting the alternative fuels. The new Cuba's economic and social policies include renewable energies, increasing its use and emphasizing those that they have bigger economic effect. Also, the integration of different renewable energies, can contribute to decreasing the dependence of the fossil fuels in order to decentralization of the actual energetic matrix and environmental problems.

Concerning to the studies about the use of emulsified fuels in Cuba, these only have point out to the emulsified diesel fuel. Therefore, could be particularly attractive to carry 
out researches that involved the emulsified technical and the biofuels obtained from non-edible crops and waste products. Biofuels will only be beneficial if they are cultivated in a sustainable way with both biodiversity and the "food vs. fuel" debate in mind [10].

The residuals obtained from the Cuban refining soybean oil industry can be used as feedstock for biofuels production. Three main by-products from the refining oil industry are obtained, as is observed in Fig.1. Soapstocks, acid oil (AO) and fatty acid distillate represents low value by-products but according to the composition, they are suitable for the production of biofuels adding value to them higher and efficiency to the vegetable oil refineries; contributing to the concept of reaching zero-waste with regards to utilization of by-products generated in the oil refineries pointed to Haslenda and Jamaludin [11].

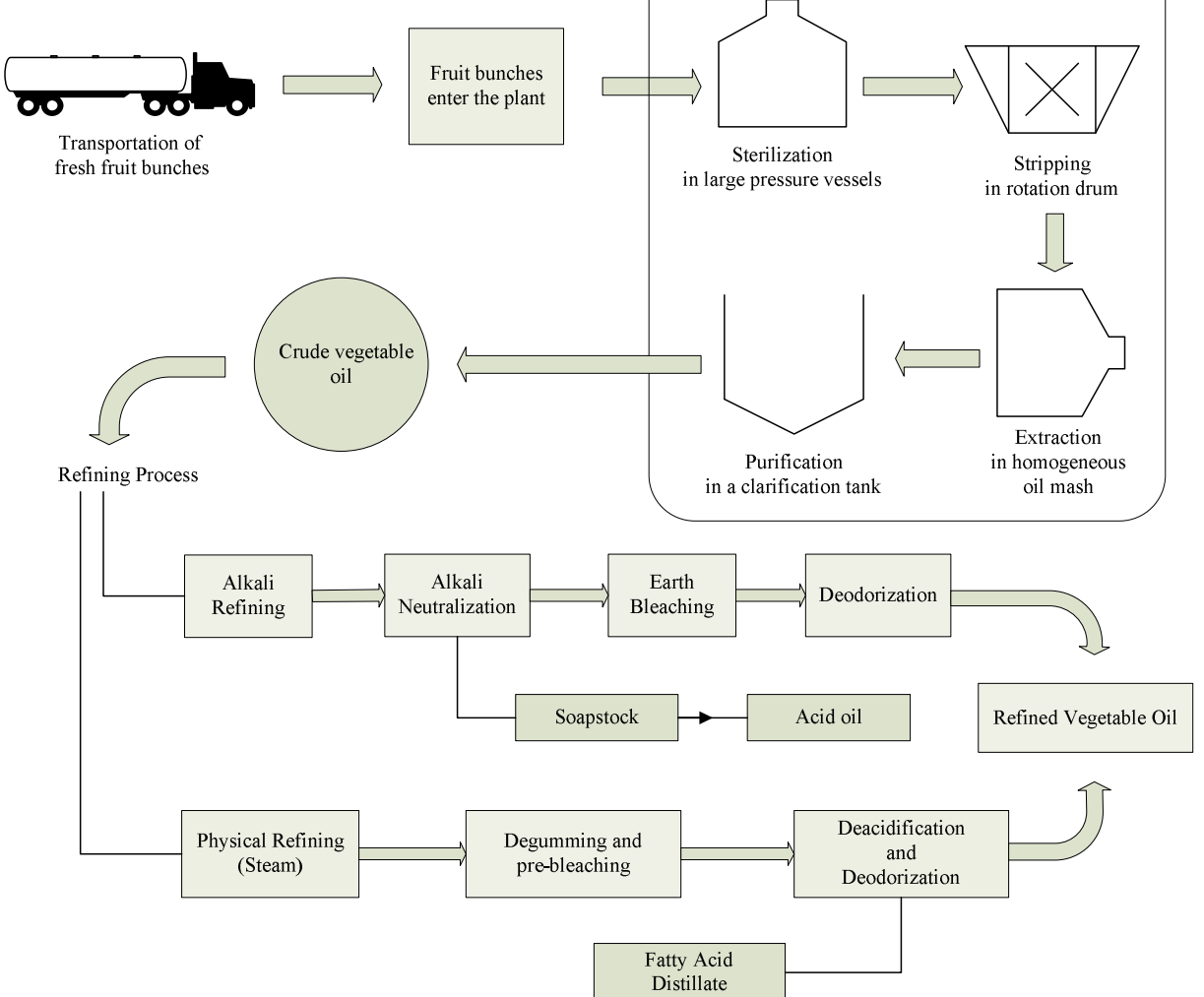

Fig. 1. Full processing flow chart for a general vegetable oil refining process

The purpose of this work is to evaluate the performance of a single cylinder diesel engine fuelled with emulsified residual oleins (ERO) and standard diesel fuel. For the characterization and comparison of the performance of the engine using the selected fuels, some parameters are measured: power output, specific fuel consumption (SFC), exhaust emissions as well as the ignition delay (ID). The last one strongly influences some parameters in the combustion process. It can be evaluated through the behavior of the in-cylinder pressure (first derivative) [12].

\section{Experimental set-up and procedures}

The emulsified residual oleins were prepared over a range of possibilities in order to obtain microemulsions. The microemulsions were prepared as ternary systems using residual oleins (RO), methanol anhydrous and the water content into $\mathrm{RO}$.

In order to select the best microemulsion for engine tests, it was necessary take into account the less as possible stabilization time during the experiments to obtain ERO, in order to decreases the energy and resources consumption.

For this reason a factorial design $2^{3}$ was developed. The selected factors (independent variables) were:

- Temperature (Low level $=50^{\circ} \mathrm{C}$ and high level $=60^{\circ} \mathrm{C}$ )

- Methanol (Low level $=10 \%$ and high level=20\%)

- Intensity (Low level $=6 \mathrm{~Hz}$ and high level=22 Hz)

The colloidal systems were prepared using an ultrasonic equipment Soniprep-120 shaking with intensity time according to analyzed variables. This technique was selected because the ultrasonic vibration technique is deemed an excellent choice for effectively preparing tiny particles in a solution at high speed [4].

Using test tubes, by visual observation of phase formation in different time intervals, the microemulsions formation were established.

The density of the isolated components and emulsified residual oleins used was evaluated using a picnometer 
standard of $25 \mathrm{~mL}$. The dynamic viscosity of the components was evaluated using a RION viscometer VT 03-F. The measures of density and viscosity of the components were to $30^{\circ} \mathrm{C}$.

The engine used in the bench tests was a Petter single cylinder direct injection diesel engine. The main engine characteristics are given in Table I. The experiments were carried out upper stoichiometric ratio $(\lambda>1)$, steady state conditions at fixed torque values $(20 \mathrm{Nm}$ and $34 \mathrm{Nm})$ and the engine speeds $(n)$ between 1300-1700 rpm.

Table I. - Characteristics of the Petter engine [13]

\begin{tabular}{|c|c|}
\hline item & value \\
\hline bore & $87.3 \mathrm{~mm}$ \\
\hline stroke & $110 \mathrm{~mm}$ \\
\hline compression ratio & $16.5 \mathrm{~s}$ \\
\hline $\begin{array}{c}\text { cubic capacity per } \\
\text { cylinder }\end{array}$ & $659 \mathrm{~cm}^{3}$ \\
\hline fuel injection timing & $\begin{array}{c}24^{\circ} \text { before Top Dead } \\
\text { Center (TDC) } \\
\text { (up to 1650 rpm) }\end{array}$ \\
\cline { 2 - 2 } & $\begin{array}{c}28^{\circ} \text { before TDC (1651- } \\
\text { 2000 rpm) }\end{array}$ \\
\hline type of cooling & water-cooled \\
\hline
\end{tabular}

The schematic diagram of the experimental setup used for the engine tests is shown in Fig.2. Two Kistler pressure sensors were installed for the in-cylinder pressure measurements: a water-cooled absolute pressure sensor type $6067 \mathrm{C}$ and a piezoresistivo absolute pressure sensor type 4075A. A Kistler signal conditioning platform with a charge amplifier type 5064 and a piezoresistivo amplifier type 4665 were also installed. A data acquisition system from National Instrument was used for the registering of the pressure measurements:

\section{- A chassis NIcompactDAQ 9174 \\ - $\quad$ Module NI 9401 (digital) \\ - $\quad$ Module NI 9215-BNC (analogical)}

A crank angle encoder Kistler type 2613B that is an optical encoder system to provide the correlation between pressure measurement signal and crank angles $\left({ }^{\circ} \mathrm{ca}\right)$ position with a resolution of $1^{\circ} \mathrm{ca}$ was used. The equipment used for measuring the exhaust NOx emissions was an emissions analyser Testo 350 with a resolution of $10 \mathrm{ppm}$.

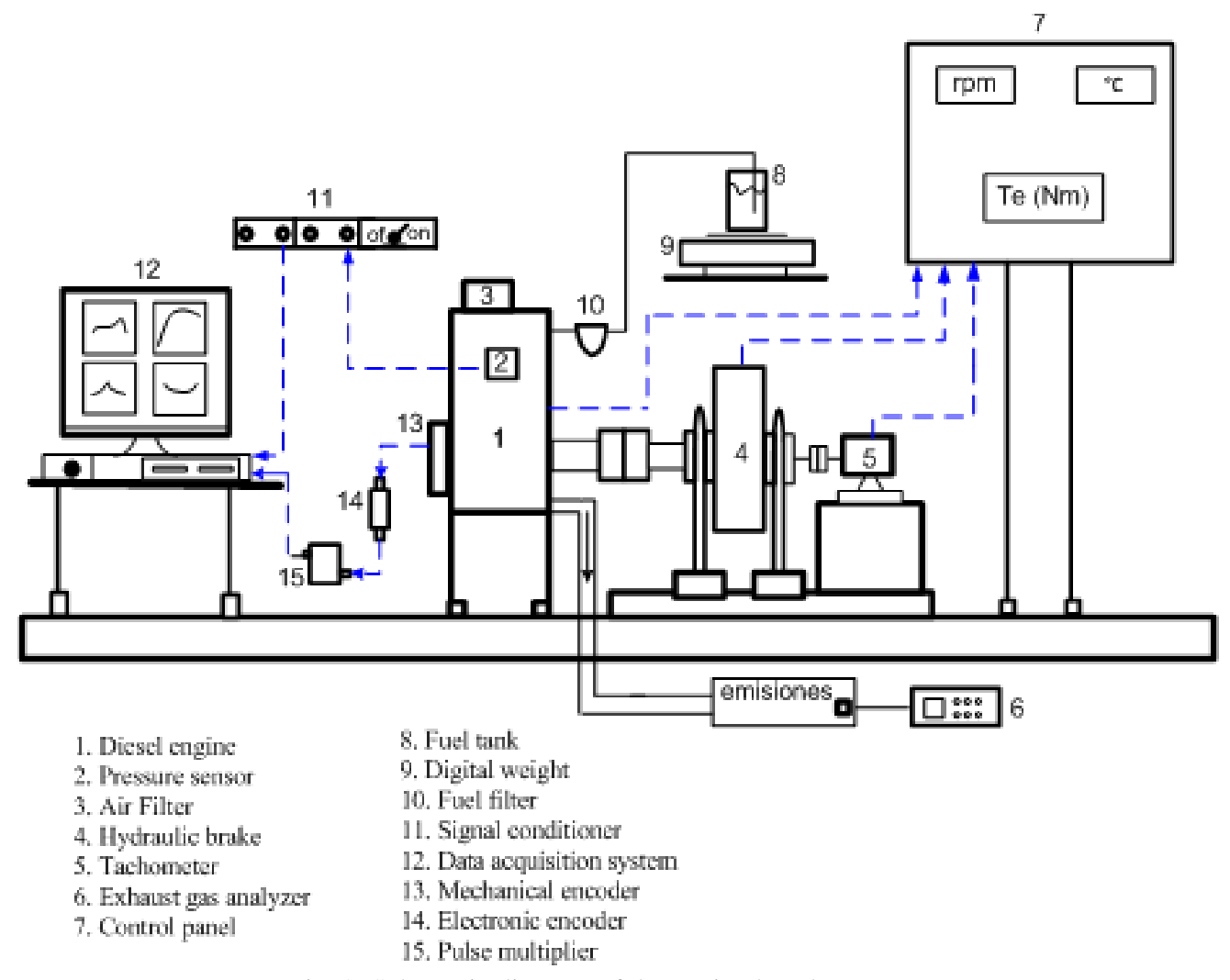

Fig. 2. Schematic diagram of the engine bench tests setup

\section{Results and Discussion}

Stability tests for the microemulsions prepared from residual oleins were not necessary, because these are thermodynamic stable systems. The microemulsions formation was detected as the formation of one phase of a very clear, transparent and totally stable liquid system. 
The results of density and viscosity measurements of the samples are shown in Table II.

Table II. - Results of viscosity and density measurements

\begin{tabular}{|c|c|c|}
\hline \multirow{2}{*}{ fuel } & \multicolumn{2}{|c|}{ physical properties } \\
\cline { 2 - 3 } & density $\left(\mathrm{g} / \mathrm{cm}^{3}\right)$ & viscosity $(\mathrm{mPa} \cdot \mathrm{s})$ \\
\hline Diesel fuel & 0.893 & 3.4 \\
\hline Residual oleins & 0.850 & 29.5 \\
\hline ERO & 0.860 & 9.5 \\
\hline
\end{tabular}

As is observed in Table II, the dynamic viscosity of ERO is $6.1 \mathrm{mPa}$ :s higher than the value found for the reference diesel fuel, while is important to point out that the difference between residual oleins (RO) and ERO was $20.0 \mathrm{mPa} \cdot \mathrm{s}$ approximately. The density measurements did not evidence significant differences among fuels.
Concerning the engine performance, the results of the power output comparison between diesel fuel and the ERO are shown in Fig.3. A slight decrease in power output was registered for ERO in every experimental test.

On the other hand, the results of specific fuel consumption for the fuels tested are shown in Fig.4. An increase in the specific fuel consumption when the ERO is used was obtained. Both behaviors are associated to the lower heating value of the residual oleins compared to diesel fuel.

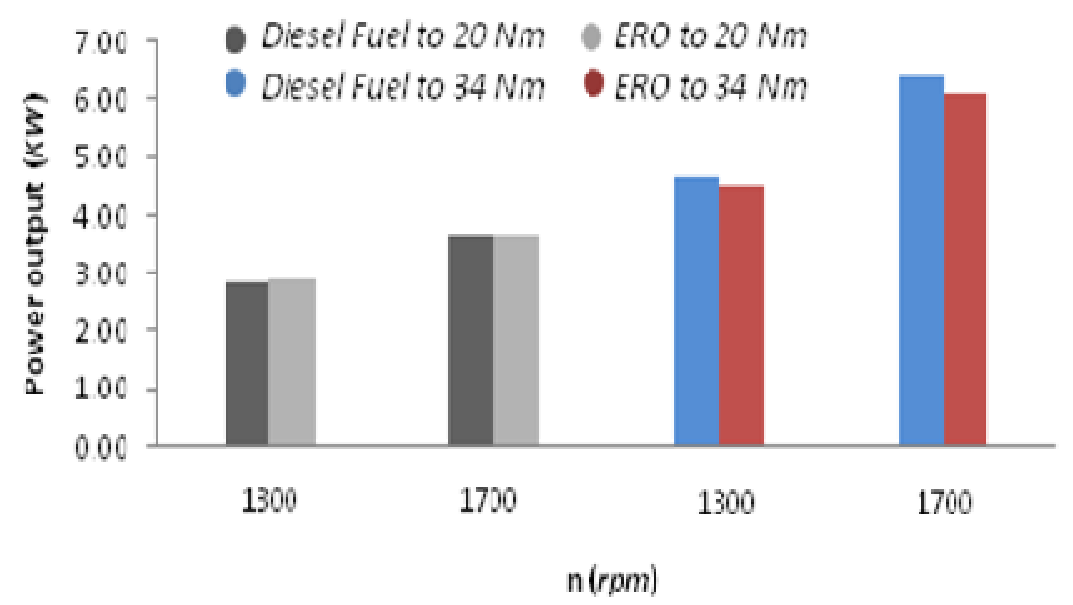

Fig. 3. Power output for the fuels tested

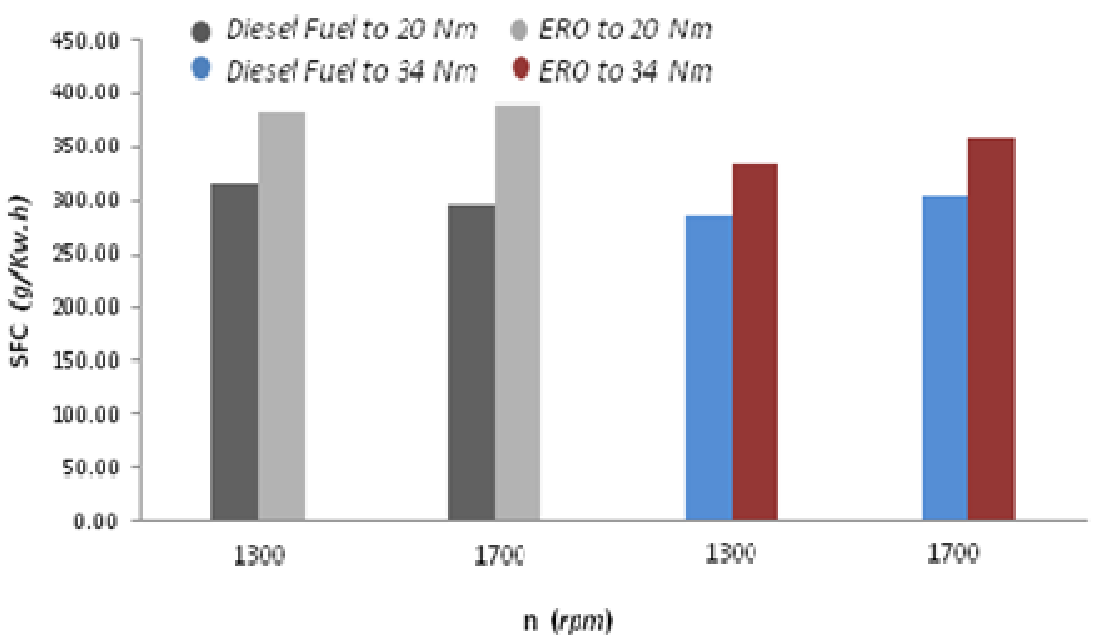

Fig. 4. Specific fuel consumption for the fuels tested

The evaluation and comparison of the ignition delay results at different engine speeds were based in the first derivative of the in-cylinder pressure [12, 13]. The comparison of the ignition delay results at different engine speeds are shown in Fig.5. An increase in the ignition delay (in crank angles) was observed to ERO compared to diesel fuel. These results can be due to a trend to lower the combustion temperature when the ERO is used, lower temperatures can lead to increase ignition delay. 


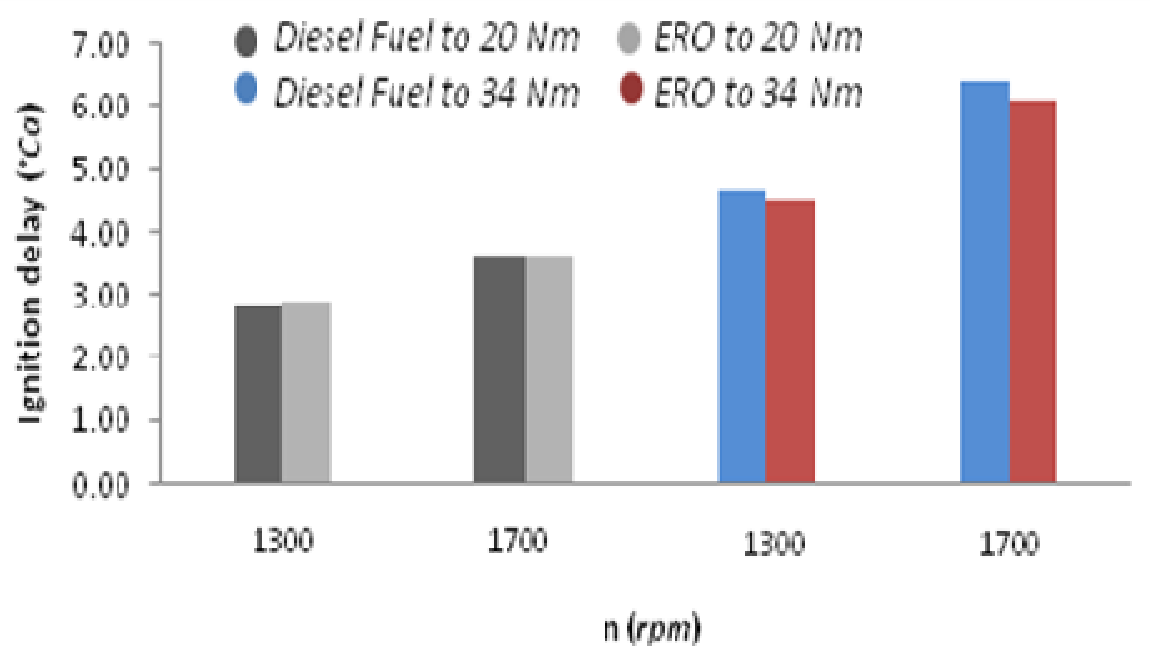

Fig. 5. Ignition delay for the fuels tested

The Nitric Oxide formation in diesel engine is due to the high combustion temperature and the availability of oxygen [8]. The variation of NOx exhaust emissions obtained is shown in Fig.6. ERO exhaust emissions are lower in NOx levels compared to diesel fuel. These results can be due to the poor volatility and lower heating value,

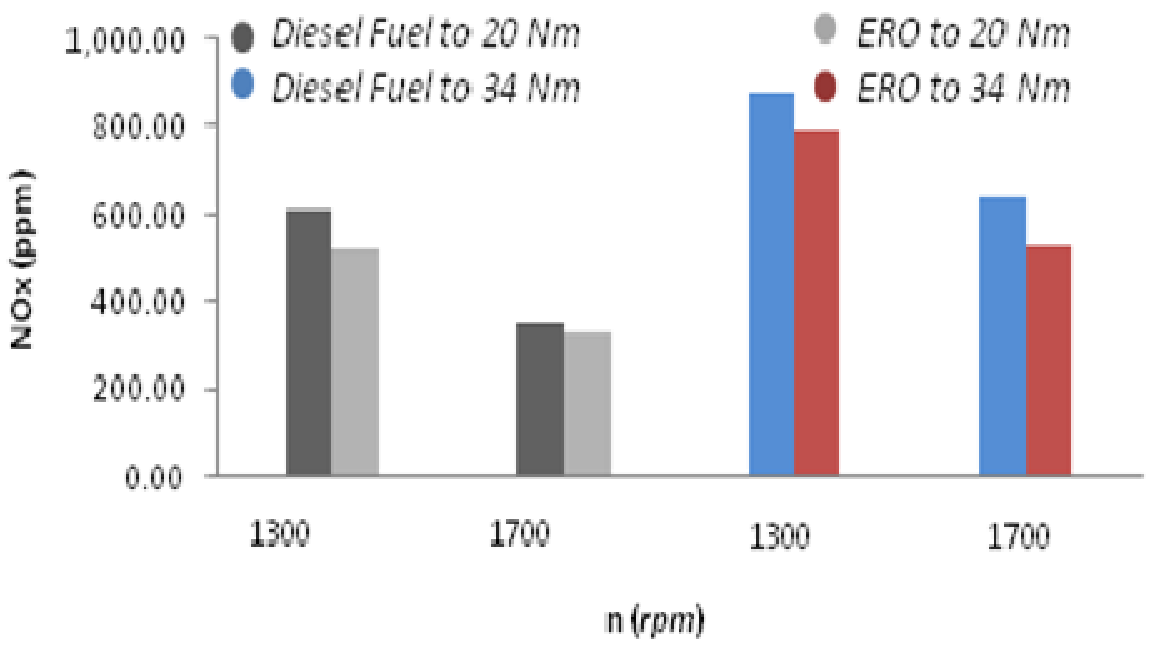

Fig. 6. NOx exhaust emissions for the fuels tested

\section{Conclusions}

The tested emulsified residual oleins shown lower power output joint to a higher specific fuel consumption related to the lower heating value of the residual oleins obtained from refining soybean oil industry compared to diesel fuel. A shorter ignition delay was observed for the emulsified residual oleins compared to diesel fuel. Also decreases in NOx emissions were observed for the emulsified residual oleins. This alternative assessed shown that the differences observed concerning to the engines performance can be partially restored with engines regulation. The use of emulsified residual oleins in order to be a partial or full alternative to the use of diesel fuel for energy production in a single cylinder diesel engine was preliminarily achieved. lower premixed and the lower combustion temperature (as a result of vaporization of water) of the ERO compared to diesel fuel. Similar behaviors is reported by Rao, et al. [14]. $\mathrm{n}(\mathrm{rpm})$

\section{Acknowledgement}

The authors wish to express their thanks to the Flemish Interuniversity Council's (VLIR) University Development Cooperation, funding an Own Initiatives Program, with whose support much of this work was performed under a project entitled "Knowledge cell on biofuels (from non-edible crops and waste products) for use in internal combustion engines".

\section{References}

[1] D. Qi, et al., "Combustion and emission characteristics of ethanol-biodiesel-water micro-emulsions used in a direct injection compression ignition engine", in Fuel 2010, Vol. 89, pp. 958-964. 
[2] A. Alahmer, et al., "Engine performance using emulsified diesel fuel", in Energy Conversion and Management 2010, Vol. 51, pp. 1708-1713.

[3] K. Subramanian, "A comparison of water-diesel emulsion and timed injection of water into the intake manifold of a diesel engine for simultaneous control of NO and smoke emissions", in Energy Conversion and Management 2011, Vol. 52, pp. 849-857.

[4] G. Kannan and R. Anand, "Experimental investigation on diesel engine with diestrol-water micro emulsions", in Energy 2011, Vol. 36, pp. 1680-1687.

[5] B. Tesfa, "Water injection effects on the performance and emission characteristics of a CI engine operating with biodiesel", in Renewable Energy 2012, Vol. 37, pp. 333 344.

[6] P. Tan, et al., "Regulated and unregulated emissions from a light-duty diesel engine with different sulfur content fuels fuel", in Fuel 2009, Vol. 88, pp. 1086-1091.

[7] K.. Senthil, et al., "The use of biofuel emulsions as fuel for diesel engines: a review", in Proc. IMechE, Part A: J. Power and Energy 2009, Vol. 223, pp. 729-742.

[8] K. Senthil, et al., "A Comparative Study of Different Methods of Using Animal Fat as a Fuel in a Compression Ignition Engine", in Journal of Engineering for Gas Turbines and Power 2006, Vol. 128, pp. 907-914.

[9] N. Yusuf, et al., "Overview on the current trends in biodiesel production", in Energy Conversion \& Management 2011, Vol. 52, pp. 2741-2751.

[10] P. Singh and A. Singh, "Production of liquid biofuels from renewable resources", in Progress in Energy and Combustion Science 2011, Vol. 37, pp. 52-68.

[11] H. Haslenda and M. Jamaludin, "Industry to Industry Byproducts Exchange Network towards zero waste in palm oil refining processes", in Resources, Conservation and Recycling 2011, Vol. 55, pp. 713-718.

[12] R. Piloto, et. al., "Engine performance of a single cylinder direct injection diesel engine fuelled with blends of Jatropha Curcas oil and standard diesel fuel", in Renewable Energies and Power Quality Journal 2013, Vol. 11, pp 1-5.

[13] E. Melo, et al., "Investigación experimental de la prestaciones de un motor monocilíndrico usando combustible diesel emulsionado", in Revista Ingeniería Energética 2013, Vol. 34, pp. 11-20.

[14] N. Rao, et al., "Performance and emission characteristics of straight vegetable oil-ethanol emulsion in a compression ignition engine", in ARPN Journal of Engineering and Applied Sciences 2012, Vol. 7, pp. 447-452. 